\title{
Guiyang Huaxi District Non-material Cultural Heritage Protection and Tourism Collaborative Model Research
}

\author{
Fei Liu ${ }^{1, a}$, Gangyin Li ${ }^{2, b, ~ * ~}$ \\ 1. Master graduate student, Research direction: the economic development in ethnic minority areas, \\ Guizhou, China \\ 2. School of Art, Guizhou University of Finance and Economics, Guizhou, China. \\ a1329418692@qq.com, *, b775430359@qq.com
}

Keywords: Intangible cultural heritage; Huaxi District; tourism development; mode.

\begin{abstract}
Intangible Cultural Heritage (hereinafter referred to as the non-heritage) and tourism integration is the current trend of industrial integration products, the use of non-heritage resources for tourism to provide a heavy cultural soil, tourism development for the protection and inheritance of the non-heritage to provide new space and opportunities. Guiyang Huaxi District has abundant non-heritage resources and its reasonable exploitation and utilization is not only one of the ways of protecting and inheriting the huaxi, exerting its value and raising the income level of local residents, but also the need of enhancing its cultural connotation and taste, enriching the tourism products and satisfying the market diversification. This article takes the Guiyang Huaxi District Cultural Project as the main research object, this paper probes into the problems existing in the inheritance of Huaxi District protection, and attempts to explore a more scientific path of the integration of the non-cultural and tourism with the Huaxi District resources, with a view to providing some reference for the development of tourism and the protection and inheritance of other areas.
\end{abstract}

\section{Introduction}

In recent years, with the continuous warming of "non-residual heat", people have agreed to develop the economic and social benefits of non-heritage tourism. "Non-Legacy" means: "the various traditional cultural manifestations that people of all nationalities have inherited and regarded as part of their cultural heritage, and the objects and places related to traditional cultural expressions, which include: traditional oral literature and language as its carrier, traditional art, dance, music, calligraphy, drama, acrobatics and acrobatics, traditional manners, Festivals and other folklore, traditional arts, medicine and calendars, traditional sports and entertainment, etc. 1

The Convention on the Protection of Intangible Cultural Heritage, formally adopted in 2003, states that "protection" means taking measures to ensure the viability of intangible cultural heritage, including recognition, filing, research, preservation, protection, advocacy, promotion and dissemination of all aspects of such heritage, mainly through formal and non-formal education and revitalization 2.From this concept, we can see that "protection" is a systematic cultural project, which involves the recognition and evaluation of intangible cultural heritage, the filing and preservation of intangible cultural heritage, the exploration and research of its cultural connotation, aesthetic value, and the propaganda and promotion of intangible cultural heritage, The nurture and protection of the inheritors and the revitalization of the inheritance and so on. Comments on strengthening the protection of intangible cultural Heritage in China in 2005 [State Council] 3 notice on strengthening the protection of cultural heritage, it is pointed out that with the development of economic globalization and the acceleration of modernization, the cultural ecology of our country has undergone great changes, intangible cultural heritage has been violently impacted, and some of the cultural heritage which relies on dictation and behavior inheritance is disappearing. Many traditional techniques are on the verge of extinction. The precious objects and materials of cultural value have been destroy or lost, and the phenomenon of excessive exploitation of intangible cultural heritage has occurred. Therefore, it is urgent to strengthen the protection of intangible cultural heritage in China. 
On the other hand, with the rapid development of China's economy, the existing forms of tourism cannot meet the diversified needs of the market, non-heritage tourism ushered in a new development opportunities. For a long time, Huaxi District's tourism is mainly natural landscape, rural pastoral scenery, historical town mainly, in many scenic spots landscape design, the cultural elements are not outstanding, "almost imperceptible cultural accumulation." "With the rapid development of society and the continuous improvement of education level, now the tourism concept of tourists has changed, from the past for the purpose of the walk to look into the" tourist destination "," Search travel strategy "of rational tourism4.

Tourists travel motives from the different cultural differences between regions, the specific performance of rational tourism is no longer interested in the reconstruction of the same scenic spots, on the contrary, has a heavy historical and cultural heritage of the attractions become more and more popular. Huaxi District's Global tourism innovation Zone and the whole-area tourism demonstration area are gradually forming, now "ten-Li Beach", "Huaxi Park" and other attractions are being endowed with new connotations. Huaxi is committed to building a new model of tourism development: Relying on historical celebrity resources, cultural resources of ethnic customs and culture, Confucius School Culture, the development of celebrity tour, ethnic Customs tour, research and learning tour and other new industries, the development of a set of tourism, leisure, tourism products for the integration of cultural tourism areas, This undoubtedly provides a good environment for the development of Huaxi District tourism.

Non-posthumous is the crystallization of national wisdom, carrying various forms of regional culture. Non-heritage tourism development can not only provide visitors with different living culture platform, but also enhance cultural awareness and identify cultural identity for tourists. Therefore, it is of great significance to develop the cultural tourism of Huaxi District to enrich its tourism products, enrich its cultural connotation and enhance its popularity.

\section{A Summary of Research in and Outside Province}

From the research direction of domestic scholars in recent years, mainly focused on the following aspects: one is the tourism development and local protection research, the second is how to develop and development model research, the third is intangible cultural heritage tourism Value evaluation research, four is intangible Cultural heritage tourism Development Strategy Research, The research of non-survivor tourism development stakeholder. Comprehensive comparison, the research on the development of non-tourism in The Guizhou province is still in its infancy, the research Foundation is weak and the results are few. In Cnk (know net) website search page input keyword for "The Guizhou province Province non-heritage tourism" for retrieval, the results showed that there were only 9 literatures on the development of non-tourism in The Guizhou province province, and the literature was downloaded and cited less, among which the most cited documents were the Mingli Zhangof the Miao-crossbow project of the central The Guizhou province5. On the development of rural characteristic sports tourism resources (4 times). Mingli Zhang through the research on the protection and inheritance of The Guizhou province folk sport--miao-crossbow project and the combination of three agricultural problems, this paper puts forward that we should take the initiative to use the unique country tourism of The Guizhou province Province as the carrier to ensure the national traditional sports can inherit the national traditional non-heritage items of their own hematopoiesis function.

Compared with the current research topics at home and abroad, the research on the heritage Protection and tourism development of The Guizhou province is focused on the status quo of non-survival and protection strategy, compared with other areas in China, the research on non-heritage tourism in The Guizhou province has not been applied much in the field survey, and the systematic study and the case study of the specific non-heritage projects are very scarce. At present, some scholars have not put forward the feasible protection mode in The Guizhou province, and the research on laws, regulations, inheritance and inheritance benefit guarantee system, special kinds of non-heritage value evaluation and tourism development are still very deficient. 


\section{The General Situation of Huaxi District and the Problems Faced in Its Inheritance}

\subsection{Overview of Huaxi District Non-Heritage}

Guiyang Huaxi District is a county-level district of Guiyang, where many nationalities are mixed together, various cultures blend and influence each other, forming a rich national cultural accumulation. Huaxi District a total of 38 ethnic minorities, the intangible cultural heritage projects are as follows:

Table 1. huaxi district intangible cultural heritage list

\begin{tabular}{|c|c|c|}
\hline Type & Project name & Number \\
\hline Folk Music & $\begin{array}{l}\text { Gao Po miao kill cattle ancestor music and dance,Huaxi District religious music, } \\
\text { Huaxi District Miao, Sister Xiao Music, Huaxi District Miao Ancient song, Huaxi } \\
\text { District Miao, Buyi suona music, Huaxi Buyi narrative song, Huaxi Buyi ancient song }\end{array}$ & 7 \\
\hline Folk Dance & $\begin{array}{l}\text { The Miao nationality silver production skill, the Gao Po town lushen dance, the Miao } \\
\text { nationality Imitate monkey's dance, the Huaxi Miao nationality jumps the field }\end{array}$ & 4 \\
\hline $\begin{array}{l}\text { Traditional } \\
\text { Opera }\end{array}$ & Qingyan lantern drama, Huaxi da Zhai Drama & 2 \\
\hline Folk Art & Gaopo Miao Embroidery Back Card & 1 \\
\hline $\begin{array}{l}\text { Traditional } \\
\text { craftsmanship }\end{array}$ & $\begin{array}{l}\text { Rose sugar production techniques, Bamboo craft, Soy products production process, } \\
\text { Soil collaboration for production process, Double flowers vinegar, Miao lace } \\
\text { production technology, Miao silver processing technology, The miao dress } \\
\text { fabrication process, Buyi paper dyeing craft, Gong tea production process, The miao } \\
\text { ethnic group production process, Glutinous rice wine brewing process, The sand clay } \\
\text { as craft, Buyi embroidery, Craft paper, Buyi glutinous rice wine brewing process, } \\
\text { Buyi bamboo weaving technology, Buyi paper dyeing embroidery production } \\
\text { techniques, Buyi bamboo weaving technology, buyi dragon production techniques, } \\
\text { Buyi chains machinery, Sand makes craft, Rose sugar manufacture craft, Buyi chains } \\
\text { machinery }\end{array}$ & 24 \\
\hline The Folk Custom & $\begin{array}{c}\text { Buyi Funeral Custom, Green Rock town Sozie, Dragon Dance, Miao bullfight, Shoot } \\
\text { back card, Miao mourning Cave }\end{array}$ & 6 \\
\hline
\end{tabular}

\subsection{Huaxi District Characteristics}

First, Huaxi has been selected at all levels of the list of non-heritage items, many types. The five Huaxi of the five forms-performing arts, traditional skills and so on are all distributed, and a large number of Huaxi District, the representative of the main focus on the traditional arts, art performance category, and the second is the value of the project of Huaxi, Huaxi part of the national and even the world has a higher historical value, aesthetic value of art, such as national non-survivor of the Miao cross-stitch embroidery; The third is facing the crisis of "inheriting the dating", through the Author field research, by the rapid development of economic activities, young people are out of the labor, for difficult to maintain the traditional skills no longer interested in subsistence. The status quo of the heritage culture of the Huaxi District listed at all levels is on the verge of "loss of human skills", and most of the traditional handicraft successors are not in existence.

\subsection{The Protection of Huaxi's Non-Heritage and Related Problems}

Intangible cultural Heritage has the characteristics of living and folk, and its protection is a recurring affair of the whole society, especially the up-and of generation after generation. In the field investigation process, the author learned that Huaxi District in the Intangible Cultural heritage protection work there are still some problems: first, the lack of rescue and protection funds, the lack of specialized researchers, resulting in quality difficult to become; second, the government departments are keen on the development and use of intangible cultural heritage, To some extent, the hidden 
danger of excessive exploitation and utilization is lack of reasonable market mechanism, it is difficult to form a benign circular protection mechanism. The third is that the owners and creators of the non-heritage culture lack a kind of "cultural consciousness", and the direct cause of this problem is that the economic benefits that the non-heritage can bring to them are weak, In addition to the lack of attention and value cognition of the intangible Cultural heritage in the field of education, education and cultural heritage protection and inheritance are divorced, some traditional skills and folk art face lost.

\subsection{Huaxi District Protection Measures Recommended}

Because of the regional and national characteristics of intangible Cultural heritage, it is decided that the protection work must be based on the land, suiting and different forms: to establish a specialized agency for the Protection of Intangible cultural heritage. The establishment of specialized agencies for the protection of Intangible cultural Heritage to strengthen the management of intangible cultural heritage. The work of the agency mainly includes making a comprehensive survey and identification of Intangible cultural heritage, laying a solid foundation for protection, and doing everything possible to collect and synthesize the information and materials that are disseminated in the civil and the Parties.

Government support. Government support is embodied in policy, economy, management and so on, mainly economic. At present, the State has clearly stipulated that the local protection funds are resolved by the governments themselves, so Huaxi District relevant government departments need to provide funds for the protection of Intangible cultural heritage.

Inheritor's protection. The protection of the inheritors is the key content of the protection of Intangible cultural Heritage, which is the best embodiment of "people-oriented" and an important aspect of "living state" protection. As a kind of "living culture", it must be extended and passed on by people.

Establish and improve the intangible Cultural heritage Benefit guarantee mechanism. Respect for social groups such as the Meng Drama group, the rights of the social people, such as folk-custom subjects, to give the necessary economic rewards and spiritual rewards to protect the rights of the local people to enjoy and use the intangible cultural heritage, and to realize their own interests, taking into account the overall interests of the Government and the State and the long-term interests of the intangible cultural Heritage, To realize the fairness in the generation, intergenerational fairness and interpersonal fairness, to ensure the intangible cultural heritage of the real interests and long-term interests of the balance.

\section{Huaxi District Protection and Toursm Cooperative Development Path Exploration}

The development of Huaxi District tourism is based on the protection and inheritance of the non-heritage, combined with its protection methods and the actual situation of the tourism market, aiming at the characteristics of the legacy, innovative development, the specific tourism development model has the following kinds

\subsection{Static Development Mode}

The construction of Huaxi Intangible Cultural Heritage Exhibition Hall or a pavilion can be embodied as a special museum,

The object of collecting, collecting and displaying a special content is to show the tourists Huaxi District Rich intangible Cultural heritage. In addition, it can be shown as the establishment of KOEP institutions and educational bases, can be developed as a special cultural tourism products, learning tourism products or become a tourist product node. In order to match the demands of modern people in pursuit of tourism experience, more participation and interactivity will be injected into the tourism development of special museums, koep institutions and educational bases.

\subsection{Active State Development Mode}

The concrete manifestation of the mode of living development is the village and ecological Museum of the Cultural Ecology Protection area. According to the characteristics of the local 
intangible cultural heritage, we can establish the Green Rock Town Ecological Museum, Meng Guan drama cultural eco-tourism area and so on, the tourism products cultivated by this model are the quality of the intangible Cultural Heritage Protection tourism development in Huaxi. Eco-Museum tourism as a cultural tourism consumer goods, this cultural tourism consumer goods not only embodies the culture of the objects, but also as a specific atmosphere, it is necessary to pay attention to the villagers participate in the development of eco-museum tourism important role.

\subsection{Non-Heritage Creative Products}

Non-heritage products mainly around the development of tourism commodities. Tourism and shopping are always accompanied by travel, tourism shopping cannot increase the tourism atmosphere, but also an important tourist motivation, tourism products compared with other commodities, its characteristics lies in its practicality, commemorative and technological nature. Such as Huaxi Miao cross-stitch, the only way to develop tourism is commercialization. The development of such non-survivor tourists refer to the following models: first, tourism products, the second is the experience of the exhibition model. Tourists to the local tourist attractions, the local culture with a strong sense of curiosity, in response to this point, you can consider a scenic spot in Huaxi to open a production experience museum.

\subsection{Comprehensive Development Mode}

The meaning of comprehensive development model has two layers, one is the development of tourism product of non-material cultural Heritage resource combination, and the other is the development of tourism product with the combination of non-material cultural heritage and material cultural heritage. Development of tourism products for Huaxi District Intangible Cultural Heritage Resources according to the evaluation results of Huaxi Intangible Cultural Heritage, if the development of the tourism resources of a single and fragmented intangible cultural heritage is like sand, it is difficult to form a product scale if the combination of these cultural factors, and the Assembly or festival as the carrier, This development of tourism products will be subject to a clear theme, the development of a strong, unique cultural characteristics. Huaxi District can develop tourism products for the theme of the Spring Festival. Including "The story", Folk lanterns Dragon Lantern, paper-cut, offerings, Mie weaving, the production of traditional food such as rose sugar production technology and technical performances, the tourism in the food, travel, shopping, entertainment and other factors are included.

\section{Conclusion}

Non-heritage elements are entering the tourism industry with their high grade historical value, artistic value, cultural value and regional characteristics, at the same time, it is an important resource to enhance the tourism product level and expand the content of the tourism project with the participation strong, the experience space is big, the entertainment is strong, and the leisure function is Non-heritage protection and inheritance in the process of integration with tourism, but also can stimulate local economic growth, improve the living standards of local residents. Combined with the current upsurge of non-heritage protection, to develop a new Huaxi District tourism project, to shape the cultural taste of the scenic spots, to enrich the cultural connotation and to shape the brand as the goal, and to integrate the elements of the culture into the tourism industry, we will be able to develop a way of integrating the development of Huaxi District Tourism and heritage protection Huaxi District projects.

\section{Acknowledgments}

This paper is supported by the research project of The Guizhou Province University of finance and economics, the research project of non-material cultural heritage tourism development path, which is supported by the project fund of huaxi district of Guiyang City. 


\section{References}

[1]. http://www.law-lib.com/law/law_view.asp?id=343073. Law of the People's Republic of China on Intangible Cultural Heritage, 2011.

[2]. UNESCO. Convention on the Protection of Intangible cultural heritage. See Shangyun. Human oral and Intangible Heritage [M] Yinchuan: Ningxia People's education press, 2004.11:412-429.

[3]. Under the state council on strengthening the protection of cultural heritage to inform [Z]. The country is sent [2205] no. 42. http://www.china.com.cn/gongbao/content-185117.htm.

[4]. Ouyang. Intangible cultural Heritage." Research on the development of non-remnant "productive tourism" [D]. Lanzhou.

[5]. mingli Zhang. Inheritance and difficulties in the project of the miao nationality of miao nationality in guizhou -- a discussion on the development of sports tourism resources in rural areas [J]. Contemporary sports technology, 2012, 2(16):79-80. 